\title{
El legado filosófico de José Ortega y Gasset en América Latina. José Gaos y el Movimiento de Historia de las Ideas*
}

\author{
Antonio Santamaría García \\ Grupo América de Estudios Sociales, \\ Universidad Carlos III de Madrid
}

Estudiar la manera en que el pensamiento de José Ortega y Gasset se traslada a América Latina supone al menos un doble ejercicio. Además de su influencia directa sobre los pensadores latinoamericanos, debemos tener en cuenta la reinterpretación que el exilio intelectual español, y fundamentalmente José Gaos, hacen de dicho pensamiento en América Latina. El objeto de este artículo es mostrar, mediante el análisis de la obra de Samuel Ramos, cómo el pensamiento de Ortega se recibe desde dos vías distintas y cómo la que pasa a través de la reinterpretación de José Gaos va a ser la más fructífera y eficiente. En segundo lugar, abordaremos también el desarrollo posterior del pensamiento de Gaos en el llamado Movimiento de Historia de las Ideas, intentando esbozar algunas hipótesis estructurales acerca de las causas del languidecimiento de este pensamiento.

\section{Introducción}

A lo largo de las próximas páginas intentaremos analizar lo que para América significa el legado filosófico de José Ortega y Gasset. Pese a que nuestra intención es de carácter general, la amplitud del tema ha determinado ciertas limitaciones autoimpuestas que, aunque no invalidan las posibilidades del estudio, sí deberán tenerse en cuenta para poder justipreciarlo en su medida. Del pensamiento de Ortega van a llegar a América influencias que tornarán en dos grandes corrientes distintas aunque complementarias. Nos referimos al Método de Análisis Generacional y al Circunstancialismo Histórico. Este trabajo se centrará esencialmente en el segundo

* Este trabajo fue concluido en mayo de 1991, de ahí que se encuentren en el texto referencias a hechos $y$ situaciones, por entonces inminentes, pero que en este momento ya han pasado. 
y, concretamente, en México, donde José Gaos va a exiliarse, o a trasterrarse -como a él le gustaba decir - reinterpretando la filosofía de Ortega a la vez que la salva (entiéndase en el más puro sentido orteguiano). Con José Gaos —dice José Luis Abellán:

“(...) Circunstancialismo y perspectivismo (...) se han convertido (...) en individualismo y personalismo cada vez mayores, sin que desaparezca nunca el fondo historicista y racionalista de base (...)".

En definitiva, Gaos toma conciencia del pensamiento de Ortega, y lo lleva al nivel de creación, lo que supone "(...) una cierta reinterpretación y originalidad". '

Hecha esta aclaración, también es preciso decir que nuestro estudio tampoco pretende ser mero análisis filosófico, siquiera de la cultura desvinculada de la realidad. En definitiva, se trata de ahondar en la reflexión latinoamericana sobre sí misma, o, mejor, en una parte de esa reflexión en un momento concreto, aunque no por parcial, poco constructiva. Por ello hemos considerado necesario hacer dos precisiones iniciales en este capítulo que permitan encuadrar el tema, desbrozando así de la parcialidad la desconexión que podría hacerla improductiva. Antes de entrar en materia, sin embargo, consideramos necesario realizar una última anotación. Como se observará más adelante, una de las pretensiones de este trabajo será intentar, a modo de conclusión, definir lo que en la actualidad parece seguir siendo válido del legado de Ortega en América, lo que hemos denominado su modernidad. Esta intención divide el artículo en dos partes bien diferenciadas en su tratamiento. En la primera se analiza la forma en que el pensamiento de Ortega se traslada a América y se desarrolla. En la segunda, tan sólo se pretende apuntar una serie de hipótesis y líneas de investigación posibles sobre aspectos no suficientemente estudiados, que nosotros no trataremos sino en forma de esbozo y en aquellos aspectos que nos resulten imprescindibles para enlazar con las conclusiones finales.

1 Abellán, José Luis: La Idea de América, Madrid, 1972, págs. 118 y 119. 


\section{El intelectual y las actividades representativas}

Plantear aquí la pregunta ¿de dónde vienen las ideas que hacen posible el surgimiento de lo nuevo? podría dar un giro radical a la intención de nuestro estudio. No es eso lo que se pretende. Sin embargo, es preciso partir de ella para entender mínimamente el contexto en que deben entenderse las ideas.

Recientemente ha dicho Ralf Dahrendorf que las ideas son condición necesaria de lo nuevo, pero nunca suficiente. Dicha condición sólo puede hallarse en las circunstancias sociales. ${ }^{2} \mathrm{Ni}$ surgen las ideas de estas últimas, como quería Marx, ni hacen por sí solas la Historia, como pretendía el Idealismo. Más correcto parece pensar, con Karl Poper, en la existencia de tres mundos en interrelación dinámica: el de los objetos físicos, el de las circunstancias espirituales y el del contenido del pensamiento producto del espíritu humano. ${ }^{3}$ Las actividades de este tercer mundo ofrecen una ocasión especial, pero también requieren una responsabilidad especial al intelectual que las ejerce como privilegio. Son las que Joseph Köning denomina "Actividades Representativas", ${ }^{4}$ idea que ya había sido expuesta por Aristóteles:

"La felicidad está en relación con el desarrollo de las mejores capacidades del hombre: el espíritu filosófico, pero no es eterna. Los dioses sólo permiten una participación reducida del hombre en ella".

Más arrogante, afirma Friedrich Nietzsche en El Anticristo: "Un pueblo es un rodeo de la naturaleza para el triunfo de casos aislados que van creando un tipo más elevado, 'el Superhombre'". ${ }^{6}$

Podríamos seguir citando ejemplos, pero lo que realmente nos interesa es la forma en que Ortega va a recoger esta idea:

"Hamlet y Don Quijote hállanse desde el comienzo de los tiempos en un tópos úperouranos, en un lugar ideal en compañía de otras in-

2 Dahrendorf, Ralf: Oportunidades Vitales, Madrid, 1983, págs. 187 y ss.

3 Poper, Karl: The Self and its Brian, London and New York, 1977.

4 Dahrendorf, R.: Oportunidades..., pág. 194.

5 Aristóteles: Ética a Nicomaco $(X, 7)$.

6 Nietzche, Friedrich: El Anticristo. 
numerables obras de arte aún desconocidas, algunas de las cuales tal vez nunca descenderán a la tierra (...) El arte tiene más de hallazgo que de construcción (...) ¿Qué conservan las cosas del espejo en que un momento reflejaron? (...) Por una parte (el poeta) es el autor de lo bello de la obra y esta autoridad se asemeja más que a nada a una pasiva vivencia (...) Por otra parte es el autor de los defectos de la obra (...) La musa íntima descubre la obra bella y el hombre circundante ha de transcribirla. Si este hombre no es también superior defrauda a su musa, la inutiliza. No basta con haber tenido la visión de un objeto estético: es menester construir (...) La inspiración (...) da sólo la posibilidad de la obra de arte. Contra ella opera la periferia del artista, el yo no-artista (...) El yo artista tiene dentro de la personalidad total una misión bien clara: superar el resto no artista (...) (que) es el que el individuo recibe de su época. Su condicionalidad histórica (...) ¿Quién triunfará?". ?

Más tarde, refiriéndose a Pío Baroja como ejemplo de poeta en la circunstancia española, Ortega responde a la pregunta:

"Baroja (...) no ha podido (...) pervivir en el medio porque su esencia consiste precisamente en la negación de éste: el medio lo absorbe, lo aniquila (...) ¡Cuántas veces no habrá sucedido esto en España! (...) En España no son tradicionales ni el arte ni el pensamiento y cada hombre nuevo que llega bien dotado (tiene que comenzar desde el principio)". ${ }^{8}$

De este modo, Ortega nos permite contextualizar en un movimiento que nace en su interior, casi narcisista; esto es, de la necesidad de salvarse él como intelectual y como hombre, conduce a la salvación del hombre y, de ésta, a la salvación de España, su circunstancia inmediata, que es vista como un mar donde naufragan los mejores espíritus. Más adelante volveremos a retomar este tema, pues lo que ahora nos interesa es llegar con Ortega a la idea o, mejor dicho, a la idea de la idea, que no es redundancia. Dice en otra parte siguiendo esta línea:

"Una idea es siempre una reacción del hombre contra una determinada situación (...) no hay, pues, ideas externas... (sólo) cuando fun-

7 Ortega y Gasset, José: Meditaciones del Quijote, Madrid, 1989, págs. 29 y ss.

8 Ortega, J.: Meditaciones..., pág. 137. 
ciona en el conjunto de la existencia cabe (pues) una historia (de las ideas)". ${ }^{9}$

Y nos interesa especialmente, pues será precisamente de aquí de donde partirá José Gaos para salvar a Ortega.

\section{Una realidad que toma conciencia de sí misma}

Decíamos que si las ideas eran condición necesaria de lo nuevo, la condición suficiente sólo podía encontrarse en las circunstancias sociales. No quisiéramos extendernos demasiado en los prolegómenos. Quizás tan sólo baste con señalar, pues, que en el período de Entreguerras se respira en el mundo un profundo sentimiento de decadencia, que no es otro que el de la cultura europea, enfrentada en una guerra con todas las características para ser considerada como una confrontación civil europea, y además no resuelta. Lo que en Europa produce obras como La Decadencia de Occidente de Oswald Spengler, culminando lo que con anterioridad ya había apuntado Nietzsche, en un mundo que se había visto arrastrado a la confrontación de una forma u otra, y que sufre sus consecuencias, producto del significado mundial que tienen los acontecimientos europeos, provoca dos reacciones de signo complementario. De un lado, la decadencia de una cultura importada, la europea, y, de otro, la autovaloración definitiva de lo propio como alternativa. Quizás es aquí donde se encuentra la primera nota negativa de un proceso que, juzgado siempre de manera positiva, no ha dado sin embargo los frutos esperados. Decía Alfonso Reyes:

"Nuestro drama tiene un escenario, un coro, un personaje (...) un tiempo (...) Llegaba tarde al banquete de la civilización europea. América vive saltando etapas, apresurando el paso y corriendo de una forma en otra, sin haber dado tiempo a que madurara del todo la forma precedente. A veces el salto es osado y la nueva forma tiene un aire de alimento retirado del fuego antes de alcanzar la plena cocción.

9 Ortega, J.: "Prólogo", en Brehier, E.: Historia de la Filosofia, T. I, Buenos Aires, 1942, págs. 29 y ss. 
La tradición ha pesado poco, y esto explica la audacia. Pero falta todavía saber sin el ritmo europeo (...) es el único tempo posible (...)".

La pregunta corre por todo el continente y no espera demasiado su respuesta:

"La laboriosa entraña de América va poco a poco mezclando esta sustancia heterogénea, y hoy por hoy existe ya una humanidad americana característica, existe un espíritu americano". ${ }^{10}$

Un sentimiento que tiene sus raíces en el punto de inflexión que significa el cambio de siglo, y que tiene en obras como Nuestra América, de José Martí, o Ariel, de José Enrique Rodo, sus reflejos más significativos, parece recibir ahora el impulso definitivo. No se trata tan sólo de una toma de conciencia sobre la propia realidad, sino que además comienza una verdadera obsesión por lo original y lo autóctono, hasta el punto del menosprecio de lo que es ajeno, que llega incluso a revertir en la creencia de que se debía adquirir un compromiso insoslayable con la cultura occidental: lo que en Europa estaba en decadencia, América, su más directa heredera, debía salvarlo, libre aún del envilecimiento que lo había deteriorado.

Se estaba cometiendo un grave error de cálculo. Ni la situación de la cultura europea era tan decadente, ni América estaba preparada para tamaña empresa. En cualquier caso, se estaban confundiendo la autoestima con la sobrevaloración de lo propio y el menosprecio de lo otro que, además, no podría considerarse como ajeno. Para una cultura como la americana, negar la cultura europea suponía desarraigo. Parece, pues, que la nueva brecha abierta entre las posibilidades y los objetivos, aun pasados los primeros años de euforia, será todavía más amplia que antes. El resultado podría expresarse en palabras de Ortega: América era incapaz de salvar su nueva circunstancia, ahora toma de conciencia desmedida de su propia realidad y de sus posibilidades. El proceso iniciado no tardará mucho en languidecer, ondulante, en un tempo que no es el que $\mathrm{Al}$ -

10 Reyes, Alfonso: Notas para una Inteligencia americana, "Sur", Buenos Aires, 1936. 
fonso Reyes propusiera, pero que él y otros intelectuales contribuyeron a crear. Más adelante, García Márquez y Octavio Paz sabrán definirlo con una palabra cuasi mágica: la Soledad.

\section{El legado filosófico de Ortega. Un método para una toma de conciencia}

\section{Breves notas sobre la filosofía de Ortega. Las "Meditaciones del Quijote"}

Ortega piensa que filosofía es una necesidad del intelecto que manifiesta un espíritu de rebeldía contra todo lo que le viene dado en el imperativo que para él supone la búsqueda de la verdad. " Esta idea lo conduce a la crítica del Idealismo y del Realismo. La fe - dice - que el hombre moderno puso en la ciencia, se ha visto defraudada, pues al enfrentarse al problema humano, ésta no ha sabido encontrarle explicación. La solución está en las ciencias del espíritu ( $s i c$ ), pero no como las entienden Realismo e Idealismo, ya que ambos cometen el error de pensar que algo existe "porque no depende de mí", cuando para que algo exista es condición indispensable que "esté dentro de mî". 12

La filosofía es en este panorama el medio que ofrece al hombre el necesario conocimiento del universo que le permita responder a sus preguntas, pues enseña que lo único que en realidad nos viene dado es la vida. Esta conclusión lo lleva a la necesidad de elaborar una Teoría de la Vida, entendida como Realidad Radical, que no sea mera descripción fenomenológica, sino verdadera Teoría de la Realidad. Ser en el Mundo - dice Ortega - es perspectiva; perspectiva que no pretende lo absoluto y que es múltiple; esto es, puede llevarse desde distintos puntos de vista. Una noción así definida, sin embargo, resultaría tan absurda como el criticado concepto idealista si no incluyese una limitación. Esa limitación no es

11 Ortega, J.: ¿Qué es Filosofia?, Madrid, 1959, Lección V.

12 Ortega, J.: Unas Lecciones de Metafísica, Madrid, 1966, Lección XIV. 
otra que la esencial circunstancia, la personalidad propia del ser humano dentro de su época, digno complemento del Yo, que es en el mundo dialécticamente enfrentado con ella. Esto es así porque la realidad, el mundo, nos vienen dados; pero el Yo no es sujeto pasivo ante ellos. Es por eso que no podemos quedarnos en mera descripción de la realidad, pues ésta, para ser, debe asumirse. Se trata, por tanto, de intentar una Teoría de la Realidad. ${ }^{13}$

Una Teoría de la Realidad debe componerse de una serie de categorías, que no son más que los conceptos que expresan el vivir y que pueden resumirse como sigue: vivir es ante todo encontrarse en el mundo. Pero en el mundo no nos encontramos de una forma vaga, sino concreta; esto es, ocupados en algo y para algo. Esto implica una finalidad que no puede ser prevista y que supone un problema. De aquí se deduce que el Yo debe hacer lo que hace y que la vida es, en fin, decisión. Ahora bien, si el Yo decide es porque tiene libertad para..., lo cual depende de la existencia de posibilidades. Las posibilidades, por su parte, no son ilimitadas, lo que quiere decir que para que haya decisión deben existir limitación y holgura. Esto es lo que expresa el concepto circunstancias. Finalmente, por lo tanto, si nuestra vida consiste en decidir lo que vamos a hacer, es que hay en ella dos niveles: ontológico, lo que significa que el ser no es estático, sino dinámico; y gnoseológico, puesto que toda razón referente a la vida es función en el tiempo histórico. ${ }^{14}$

No va por tanto Ortega contra el racionalismo clásico por asumir una posición irracionalista, sino porque ve en él la razón al margen de la vida (de ahí que su filosofía reciba también el nombre de Raciovitalismo). La razón para Ortega funciona dentro del individuo, no desarraigada de él, y lo hace, además, en las propias circunstancias, de forma que es razón histórica, ya que la vida es temporeidad. De nuevo esta razón, por tanto, es más que mera descripción, ya que pretende el descubrimiento de una totalidad que es histórica: la vida del hombre que —-según sus palabras- "va siendo y dessiendo", descubriendo continuamente nuevos horizontes.

13 Ortega, J.: "Perspectiva y Verdad", en El Espectador, Madrid, 1916.

14 Ortega, J.: ¿Qué es Filosofía?, Lecciones X y XI. 
Estas son, en esbozo, las líneas básicas del pensamiento de Ortega. No obstante, lo que a nosotros interesa de ellas son las ideas más marginales, su punto de partida, y no tanto su ulterior desarrollo. Nos referimos concretamente al primer Ortega, al de las Meditaciones del Quijote, publicadas en 1914, y lo hacemos por dos razones esenciales. Primero, porque en ellas está el germen, con pocas variaciones, de lo que será luego todo su pensamiento. Segundo, porque es de los presupuestos originarios que en ellas se encuentran de donde partirá José Gaos en su intento, ya en México, de defender la posibilidad de un pensamiento, no ya español, sino hispanoamericano.

Ortega reacciona en Meditaciones del Quijote contra el neokantismo filosófico imperante por entonces, así como contra la idea que más adelante expresaría Ramón Menéndez Pidal al referirse a los progresistas españoles:

“(...) Siempre se mostraron muy poco inclinados a estudiar y afirmar en las tradiciones históricas aspectos coincidentes con la propia ideología". ${ }^{15}$

Para Ortega es idea clave reaccionar contra esta posición y $\mathrm{Me}$ ditaciones del Quijote aparece, no ya como una obra más en una tradición de largo desarrollo en España, sino también como justificación de la existencia y necesidad de la misma. Es decir, como parte, síntesis y método a la vez de la "(...) búsqueda de una filosofía que aclare el sentido y el destino de lo español (...)", que debe encontrarse, como se ha dicho, en la propia vida individual, realidad primaria o radical; en el diálogo del Yo con las circunstancias:

"Yo soy yo y mis circunstancias, y si no las salvo a ellas no me salvo yo".

En un mundo que aún conserva parte del lastre determinista, que niega al hombre capacidad alguna para actuar frente al medio; pero en un mundo también de larga tradición crítica contra esta idea,

15 Menéndez Pidal, Ramón: Los Españoles en la Historia, Madrid, 1959, pág. 218.

16 Ortega, J.: Meditaciones..., pág. 25. 
Ortega ofrece una salida: ver al hombre como sujeto activo de la Historia, capaz de hacer frente a la necesaria tarea de reconstrucción. Urge, pues, descubrir lo que en España hace fracasar a los hombres -dice Ortega - y para ello es preciso ver España como objeto de un fracaso. Sólo así podremos poner verdadero remedio. Es necesario - continúa - hacer arder la apariencia de España, que desde hace años ha ido ocultando su esencia entre accidentes, para recuperar en ella su intención original, la esencia desbrozada de todo lo que le ha impedido el movimiento. Para ello debemos ir contra la tradición (no confundir con la tradición intelectual a la que nos referíamos con anterioridad), más allá de ella. Esto es lo que Ortega llama Patriotismo Esencial. ${ }^{17}$

La nueva actitud que, como decíamos, surge de la necesidad vital que Ortega tiene de salvarse como pensador, como español y como hombre fluye desde dentro hacia fuera, desde abajo hacia arriba y desde el presente hacia el pasado y hacia el futuro. Supone, pues, un perspectivismo integracional.

"Su doctrina de las circunstancias lleva a Ortega a una filosofía de lo español (...) (que) implica una preocupación por la historia de esa circunstancia... (por) su evolución intelectual... (por) la Historia de las Ideas (...) (que) tenía tradición en España (...) (y en la que) $M e$ ditaciones del Quijote (no será) sino un libro más". ${ }^{18}$

Así ha definido José Luis Abellán el significado del primer Ortega en la búsqueda de un sentido de lo español. Evidentemente $M e$ ditaciones del Quijote es mucho más que eso, pero lo que aquí se pretende no es hacer un estudio de la obra, sino señalar cuál es, en síntesis, su legado para América.

\section{Samuel Ramos y la primera influencia de Ortega en América}

No son muchos los contactos directos que Ortega tuvo con América. En realidad se reducen a poco más que las visitas realizadas a

17 Ibídem, págs. 134-141.

18 Abellán, J. L.: La Idea..., págs. 113 y 114. 
la Argentina, donde imparte algunas conferencias y escribe ciertos artículos con pocas pretensiones, casi siempre impresiones de carácter primario, al estilo de Kesselring y Waldo Frank, cuya influencia es palpable por aquel entonces en varios pensadores latinoamericanos. Es el caso de Ezequiel Martínez Estrada y su Radiografía de la Pampa, de Samuel Ramos e, incluso, lo será más tarde de Octavio Paz en la primera parte de El Laberinto de la Soledad. La influencia directa de Ortega no es, sin embargo, desestimable. Debemos recordar, por ejemplo, que Victoria Ocampo, una de las mentoras de la revista Sur, expresará tras haber asistido a las conferencias de Ortega, que sólo tras haberle escuchado se había dado cuenta de que "se podía pensar en Castellano" ( ic ). Con ella, en la Argentina, toda la denominada Generación del 36, la generación de Jorge Luis Borges, quedará impregnada por el pensamiento de Ortega.

Si bien la influencia directa de Ortega no puede ser menospreciada, su mayor impacto no llegará sino de forma indirecta, a través de sus discípulos y, sobre todo, a través de José Gaos, con el exilio español en México tras la Guerra Civil. Más adelante abordaremos este tema en profundidad; ahora quisiéramos referimos a la obra de otro pensador, esencial a nuestro modo de ver tanto para comprender la forma en que el legado de Ortega se traslada a América, puesto que habría leído a Ortega antes de que Gaos llegase a México, como por su propia influencia posterior, nunca valorada suficientemente, pero clave en el pensamiento hispanoamericano. Nos referimos al mexicano Samuel Ramos y, concretamente, a su obra El perfil del hombre y la cultura en México.

Esta obra supone, según nuestro entender, un verdadero hito en la articulación del pensamiento en lengua española. Como es común, Ramos parte en ella de la necesidad de encontrar un sentido de lo mexicano, de lo americano por extrapolación, adelantándose en muchos casos a posteriores y fructíferas escuelas filosóficas y sociológicas del Psicoanálisis. Dice así que el mexicano adolece de un profundo sentimiento de inferioridad producto de "(...) una verdadera inadaptación de los recursos a los fines".

Pero, para liberarse de él, el mexicano no reacciona afrontando la realidad: 
“(...) Los individuos que contraen el sentimiento de inferioridad adquieren una psicología muy especial (...) Todas sus actitudes tienden a darle(s) una ilusión de superioridad que para los demás no existe. Inconscientemente sustituye(n) su ser auténtico por el de un personaje ficticio (...) Vive(n), pues, una mentira".

Efectivamente, urde el mexicano como solución a sus problemas una vida de mentira que tiene su origen histórico tanto en la colonia como en la independencia. Durante toda su historia América y concretamente México, ha fraguado su propia autodenigración, producto de una cultura que, aunque necesariamente tenía que ser derivada, abusó de las importaciones. Tanto el exceso de éstas como la reacción posterior contra ellas, consecuencia de sus continuos fracasos en la propia realidad, son nocivos para México. La única conclusión que cabe entonces es afirmar que éste no ha afrontado jamás su verdadera realidad, bien por exceso, bien por defecto.

Por si esto fuera poco - continúa Ramos - la historia de México no se ha caracterizado por una sucesión de hechos verdaderamente significativos socialmente hablando, sino que se ha limitado a seguir un círculo antihistórico, sin apenas espiral, que ha impedido toda espontaneidad en sus hombres. Así el mexicano aparece, como sucedía con el español, desmembrado de su realidad, como “(...) un átomo rebelde cuyo movimiento tiende a separarlo de su centro natural de gravitación". ${ }^{20}$

La cultura española no tuvo fuerza suficiente para vencer al nuevo medio en que estaba siendo trasplantada. Es el dilema de $\mathrm{Si}$ món Bolívar:

"Siendo nosotros americanos por nacimiento, nuestros derechos (son) los de Europa", ${ }^{21}$

aunque, eso sí, con una nueva actitud, más constructiva, que ya no se limita a rechazar el pasado, sino que intenta asumirlo co-

19 Ramos, Samuel: El perfil del hombre y la cultura en México, Buenos Aires, página 12.

20 Ibídem, pág. 36.

21 Bolívar, Simón: Carta de Jamaica, 1815 (hay varias ediciones). 
mo conformador incuestionable del ser y de la vida nacional del americano que quiere afrontar realmente el futuro.

Samuel Ramos analiza la historia de México desde esta nueva perspectiva, llegando a la conclusión de que sólo a través de ella será posible la salvación de lo mexicano, como de lo americano en general, por medio de una toma de conciencia sincera de la propia realidad, presente y pasada, que ofrezca al hombre los elementos necesarios para hacer frente al peligro que se cierne sobre él: el progreso técnico y el utilitarismo, contra lo que José Enrique Rodó ya había reaccionado a principios de siglo. Por eso "El ideal de nuestra cultura debe ser la realización de un nuevo humanismo (en este sentido)". 22

La filosofía, el pensamiento, las ideas en general, deben jugar un papel esencial en el proceso, ejerciendo fundamentalmente una labor educadora. En Ramos, pues, se halla claramente lo que decía Abellán:

"En América encontramos fenómenos parecidos (a los de España): (...) preocupación por lo autóctono, por las distintas circunstancias nacionales (...), por su destino como pueblo". ${ }^{23}$

Pero en lo que Abellán se equivoca es en el juicio de la influencia directa de Ortega sobre Ramos, cuando el segundo es, precisamente, el más claro ejemplo de lo que con anterioridad apuntábamos y que el mismo Abellán no duda: la verdadera influencia de Ortega vendrá por medio de Gaos. Los problemas que Ramos plantea no tienen por qué llegarle a través de Ortega, puesto que no han sido sacados a la luz por éste, sino que forman parte de una tradición cultural que es común para los dos. Las soluciones a las preguntas, sin embargo, no las obtendrá en Ortega hasta más tarde. Para entonces ya está en México José Gaos.

"Una generación intelectual, que comenzó a actuar públicamente entre 1925 y 1930, se sentía disconforme con el romanticismo filosófico de Caso y Vasconcelos. Después de una revisión crítica de sus doctrinas, encontraba infundado el antiintelectualismo, pero tampoco

22 Ramos, S.: El Perfil..., pág. 80.

23 Abellán, J. L.: La Idea..., pág. 115. 
quería volver al racionalismo clásico. En esta perplejidad comienzan a llegar a México los libros de Ortega y Gasset, y en el primero de ellos, las Meditaciones del Quijote, encuentra solución al conflicto en la doctrina de la razón vital. Por otra parte, a causa de la Revolución se había operado un cambio intelectual que, iniciado en el año 1915, se había ido aclarando en las conciencias y podía definirse en estos términos: México había sido descubierto. Era un movimiento nacionalista que se extendía poco a poco en la cultura mexicana (...), la filosofía no parecía caber en este cuadro ideal del nacionalismo, porque ella ha pretendido siempre colocarse en un punto de vista universal humano, rebelde a las determinaciones concretas del espacio y del tiempo, es decir, a la historia. Ortega y Gasset vino a resolver el problema mostrando la historicidad de la filosofía (...) Aquella generación mexicana encontraba la justificación epistemológica de una filosofía nacional". ${ }^{24}$

Ramos encontraba así en Ortega respuesta a la que fuera su gran preocupación: la búsqueda de una filosofía que pudiera utilizarse como herramienta para nuestra comprensión, que permitiera al mexicano dejar de pensar como extranjero y comenzar a ver el mundo desde su propia perspectiva. Un pensamiento que tenga como objeto inmediato el contorno mexicano, como única forma de incluir su vida, su historia, su cultura en la historia universal, con el mismo parangón que el resto de las historias nacionales, superando el sentimiento de inferioridad y ofreciendo al fin la posibilidad de pensar, que es necesidad vital del hombre y único medio para que sus proyectos dejen de malograrse cuando se enfrentan a la realidad por falta de reflexión, y de que los intelectuales abandonen su huida aparente de la realidad que les rodea. En su defensa dice Ramos:

"El intelectual, al buscar en torno suyo, encontraba que la realidad ambiente era la muerte y, al defender su fe, su porción de cultura, defendía un fermento de vida". ${ }^{25}$

Ante este problema Ortega había dicho: "La muerte de la muerte es la vida". ${ }^{26}$ Y Ramos consigue, con él, encontrar solución al imperativo:

24 Ramos, S.: Historia de la Filosofía en México, México, 1934, pág. 140.

25 Ramos, S.: El perfil..., pág. 80.

26 Ortega, J.: Meditaciones..., pág. 28. 
"No queremos una cultura sin vida, no una vida sin cultura, sino una cultura viviente (...) (que) nos permita comprender y estimar mejor la realidad mexicana". 27

Antes, sin embargo, José Gaos había llegado a México, y allí va a completar la perspectiva historicista del circunstancialismo de Ortega.

\section{José Gaos y la reinterpretación del pensamiento de Ortega en América}

José Gaos había sido el discípulo predilecto de Ortega hasta que decide abandonar la Agrupación al Servicio de La República, que éste lidera, para ingresar en el Partido Socialista. Lo que en principio es un distanciamiento político y quizás gracias a ello y al alejamiento que supone el exilio de Gaos en México tras la Guerra Civil Española, terminará en cierto distanciamiento filosófico, que debe ser entendido en un sentido positivo, ya que conseguirá ensanchar el radio de acción del pensamiento de Ortega, completándolo con mayor amplitud de miras. En efecto, Gaos llega a México y va a poner a prueba lo que ha aprendido. La necesidad ya no es sólo salvar lo español encontrándole un sentido, sino salvar lo hispano de ambos lados del Atlántico. Con anterioridad veíamos cómo Abellán sostenía que Gaos toma conciencia del pensamiento del maestro. Pero, en realidad, lo que Gaos hace es dar un paso aún más importante para que dicho pensamiento cobre eficacia; esto es, aplica la conciencia que de él había tomado, y no sin la necesaria crítica, que el mismo Ortega considera paso ineludible para que la labor intelectual sea fructífera. Gaos - continúa Abellán - ve la necesidad de salvar la enorme circunstancia que para él suponía el pensamiento del maestro, y para ello va a utilizar su filosofía como medio para reivindicar la posibilidad de un pensamiento hispano. ${ }^{28}$ Lo mismo que veíamos en Ortega sucede, pues, con Gaos: partien-

27 Ramos, S.: El perfil..., pág. 96.

28 Abellán, J. L.: La Idea.... págs. 118-120. 
do de una necesidad personal reivindicará la existencia y necesidad de un pensamiento hispano.

La pregunta que Gaos se plantea es si puede hablarse de una historia de la filosofía en México y, por extrapolación, en América. Previo sondeo de la realidad, llega a la siguiente conclusión:

"La historia de la filosofía en México viene hace unos años consistiendo, no exclusivamente, en una actividad enderezada a elaborar, por un lado, una completa historia de las ideas en México, y, por otro lado, una filosofía del mexicano y de lo mexicano". ${ }^{29}$

Lo que ahora nos interesa es la primera de las necesidades expuestas por Gaos, porque es cuestión previa y porque entrar en la segunda supondría alejarnos del objetivo de este estudio. Partiendo de la doctrina de la circunstancia de Ortega, Gaos va a enfrentar el problema que ya veíamos en el maestro, llegando a la conclusión de que para su solución hay que partir del pensamiento del primer Ortega y ahondar en el sentido historicista del circunstancialismo. La historia de la filosofía en México - dice- es parte de la historia de la filosofía en general, pero entre ambas hay un conflicto: aquélla no puede ser porque no es original. A Gaos esta idea le parece absurda, por lo que supone debe haber un error en sus premisas. Para averiguarlo es preciso revisarlas.

En los países de lengua española —continúa Gaos - se llama pensadores a los filósofos. Con este término, sin embargo, también se designa a los teóricos de las ciencias humanas e históricas, así como a los de las ciencias naturales y exactas y a los que cultivan la crítica literaria y del arte y la literatura de las ideas. Los pensadores se caracterizan, por tanto, por el ejercicio del magisterio y por la incorporación del pensamiento a la acción. ${ }^{30}$ Esto equivale a considerar que la historia de la filosofía en México debe ser estudiada como parte de la historia del pensamiento que, a su vez, es parte de la historia de las ideas, no entendiéndolas como algo abstracto,

29 Gaos, José: En torno a la Filosofía Mexicana, México, 1952 (2 vols.), Vol. I, pág. 7.

30 Ibídem, págs. 15 y 16. 
sino - ya lo veíamos - vinculadas a su situación. Esto es, sabiendo que la historia de la ideas sólo existe en tanto que es parte de la "Historia Una", teniendo como objeto explicar y comprender complementariamente el resto de las partes del todo.

El eje central del pensamiento de Gaos va a ser, pues, el tema de las relaciones entre la filosofía y la historia; de ahí que con anterioridad afirmásemos que la respuesta a la necesidad expresada por Ramos estaba en Gaos antes que en Ortega, quien en su evolución, como ya vimos, es mucho más que eso, si no se desvía de ello. Del método que el primer Ortega ofrece en Meditaciones del Quijote y, posteriormente, en Prólogo para Alemanes, Gaos utiliza los instrumentos que permiten un análisis retrospectivo de la evolución histórica de las ideas en México dentro de la historia de México.

Sondear la historia de México supone darse cuenta de que existen varias etapas que es preciso distinguir como única forma de dar respuesta al dilema planteado. Existe una primera etapa de importación de ideas con dos momentos, uno en el que la importación se realiza desde fuera, con espíritu metropolitano, y otro en que lo hace desde dentro, con espontaneidad. Importar con espíritu nacional - dice Gaos- supone una inserción de dichas importaciones en lo nacional que no será, sin embargo, más que el paso previo para la inserción de lo nacional en lo importado. Si el momento anterior había sido cumplido por autores como Sor Juana Inés de la Cruz y Siguienza y Góngora, quienes abren camino a los jesuitas del siglo XVIII, los cuales preparan la independencia; este último será cubierto por el Positivismo, que es capaz de cambiar el lema comtiano "orden, progreso y amor" por el más adecuado a la vida nacional "orden, progreso y libertad". ${ }^{31}$

Hablar en estos términos supone reconocer una doble originalidad en el pensamiento mexicano, pues no sólo se observan filosofías originales en la historia de las ideas debidas a los mexicanos, sino también aportaciones originales a filosofías no debidas a mexicanos, lo que conduce a un segundo problema, paralelo aunque distinto, pues

31 Ibídem, págs. 50 y ss. 
“(...) (si) la primera originalidad queda dentro del ámbito de la historia de la filosofía (...), la segunda se presenta como parte de la originalidad de las culturas, relativamente unas a otras, como parte de la filosofía de la cultura (...) (Si) para justipreciar la primera (...) ha sido necesaria la articulación de la historia de la filosofía mediante categorías autóctonas, para justipreciar la segunda no será necesario precisamente mucho menos". 32

Lo grave de llegar a una conclusión como ésta es que Gaos se da cuenta de que el problema no se halla sólo en la negación de la filosofía, de la historia y de la cultura propias que se realiza desde fuera, lo que podría tener su lógica, sino en la que se lleva a cabo desde dentro. Los propios mexicanos se niegan a sí mismos manteniendo actitudes semejantes y lo hacen, además, a priori; esto es, sin haber estudiado antes las manifestaciones. Gaos habla entonces de la necesidad de "inventar" (sic), estudiar y criticar los textos para, a continuación, articularlos por medio de categorías históricas autóctonas, ya que sólo a través de la historia se conseguirá la necesaria síntesis que demuestre la existencia de un pensamiento mexicano original.

No se limita Gaos, además, a exponer sus conclusiones en términos teóricos, sino que decide afrontar en la práctica la necesidad de revalorizar lo que él llama el pensamiento en lengua española. Para ello crea el Seminario para el Estudio del Pensamiento en los Países de Habla Española en la Casa de España, actualmente Colegio de México, desde donde pretende fomentar y articular el estudio del tema en toda América. De entre sus seguidores comienza a destacar entonces la figura de Leopoldo Zea, fundador del Grupo Hiperión, quien empieza a afirmar con insistencia la existencia de una filosofía original mexicana.

A pesar de que Gaos considera a Zea su discípulo más aventajado, aquí comienza a separarse de él, previendo los efectos negativos que su forma de actuar podría tener. Ciertamente, del pensamiento de Gaos podía deducirse la existencia de una filosofía mexicana, sin embargo, hay que hacer algunas precisiones al res-

32 Ibidem, págs. 68 y 69. 
pecto. Dice José Luis Abellán que cuando Gaos estudia el proceso histórico del pensamiento en lengua española descubre dos etapas en el pensamiento hispanoamericano, una primera de dependencia y una segunda de independencia, pero que la de independencia se produce dentro de un movimiento general de independencia ideológica que tiene su origen en la Ilustración española. En efecto, tanto en España como en América coincide la existencia de un pensamiento liberal y antiimperialista, que si bien triunfa en América, fracasa en España, convertida así en "la última colonia de sí misma". ${ }^{33} \mathrm{La}$ separación que tradicionalmente ha querido verse entre coloniales y metropolitanos es, por tanto, falsa, al menos en este sentido, por lo que debe realizarse una labor de revisión con nuevas y más amplias perspectivas que contemplen la verdadera distinción, pues ésta se produce, en realidad, entre los partidarios del pasado y los partidarios de la renovación en ambos lados del Atlántico. ${ }^{34}$ Con esta idea Gaos había roto no sólo los obstáculos históricos, sino también la barrera físico-geográfica para la existencia de un pensamiento hispano.

El movimiento que triunfa con la Ilustración en España y América no es, además, un movimiento aislado. Forma parte de una tendencia general al inmanentismo que puede apreciarse en la evolución de la filosofía, caracterizada por una preocupación creciente por las cosas del mundo y de la vida, que abandona la mera elucubración esencialista. No osa Gaos pronunciarse, sin embargo, por la existencia de una filosofía en México o en América como producto de esta tendencia, cuestión que estima sólo la historia puede decidir, limitándose a realizar su aportación a la posibilidad de la misma. Siguiendo la división por etapas que Wilhelm Dilthey hace de la filosofía, ${ }^{35}$ Gaos estima que ésta ha abandonado su afán sistematizador, metódico y metafísico para preocuparse por cuestiones más cercanas a la moral, a la cultura y a la vida, asistemáticas, ametódicas y ametafísicas, llegando incluso a preguntarse si no podría considerarse aquella primera etapa como un estadio inferior y pre-

33 Ibídem, pág. 25.

34 Abellan, J. L.: La Idea..., págs. 118-120.

35 Dilthey, Wilhelm: Introducción a las Ciencias del Espíritu, México, 1944. 
cedente de esta segunda. Aquí de nuevo es interesante recordar la vinculación de Gaos con Ortega, puesto que si ya decíamos que en su evolución el primero se separa del segundo, no puede dejar de mencionarse que al final de su vida Ortega reconocerá que, de haber leído antes a Dilthey, habría variado significativamente su pensamiento. Con ello Ortega estaba reconociendo implícitamente la labor de su discípulo.

Volviendo a Gaos, las conclusiones alcanzadas lo conducían a afirmar que, o se reconocía que la filosofía acabó con la primera de las etapas que marcara Dilthey, o se integraba dentro de la misma a los pensadores hispanos. Los Rodó, Vasconcelos, Unamuno y el mismo Ortega, debían ser considerados al mismo nivel que Schopenhauer, Nietzsche, Bergson, etc. independientemente de que su pensamiento fuese o no filosófico. Con ello Gaos reafirma la historia de la filosofía como estamento incluso superior a la filosofía misma, ya que hace en ella la labor de selección y síntesis que permite el descubrimiento de las verdades al servicio de la vida, formada por todas aquellas aportaciones válidas de las diferentes épocas, espacios y autores, superada su circunstancia. Gaos salva así la posibilidad de un pensamiento y de una filosofía hispanas que, sin embargo, aún está por hacer y sobre la que sólo la historia podrá decidir (de ahí que se separe del movimiento que él mismo había creado), al tiempo que consigue salvar al propio Ortega, a quien otros pensadores, como Bergson, habían tildado de mero periodista.

\section{Algunas notas acerca de una obsesión radical. Del Movimiento de Historia de las Ideas al Pensamiento de la Liberación}

Al mismo tiempo que Gaos creía ver completada su tarea, entendida como punto de arranque de una labor que aún estaba por hacerse y que, en cualquiera de los casos, sólo la historia podría completar, veíamos cómo comenzaba a ser defraudado por el mismo proceso que él había puesto en marcha, pero que volvía a repetir errores pasados, confundiendo los medios con los fines. Decíamos 
que el pensamiento y la actitud de Gaos en México iba a provocar el surgimiento de un movimiento de estudio y de reivindicación del pensamiento americano, que será conocido como Movimiento de Historia de las Ideas. No es objetivo de este trabajo analizar su significado, sino sólo esbozar aquellos aspectos que deben ser entendidos para poder comprender lo que hemos denominado la modernidad del legado de Ortega en América.

Ya apuntábamos la labor iniciada por el Seminario para el Estudio del Pensamiento en los Países de Habla Española, así como el trabajo que Leopoldo Zea desarrollaba en el mismo, tanto a través de sus obras, como por medio de la creación de distintos órganos que respondían a los mismos objetivos. Junto al citado Grupo Hiperión hay que mencionar al Comité de Estudios de Historia de las Ideas, propuesto por Zea al Instituto Panamericano de Geografía e Historia, el nacimiento de fondos editoriales para la publicación de los estudios que fuesen surgiendo de la labor, como la colección Tierra Firme del Fondo de Cultura Económica, etc.

El movimiento tendrá rápidas respuestas en el resto de América. En Argentina comienzan a trabajar en esta línea Francisco Romero y Coriolano Alberini, entre otros; en Brasil se reúne en 1950 el Congreso de Filosofía de Sao Paulo bajo la dirección de Cruz Costa. En 1956, finalmente, se realiza en Puerto Rico el Primer Seminario de Historia de las Ideas con el que, según Arturo Ardao, se certifica la mayoría de edad del movimiento, planificando unas líneas de actuación que pueden sintetizarse en el intento de establecer las diferencias existentes entre la filosofía anglosajona y española, a la vez que se reforzaban los lazos entre los filosofos españoles y los americanos; en el ahondamiento en la reflexión sobre las relaciones entre los procesos ideológicos y materiales; en el reforzamiento de las conexiones entre el proceso de emancipación mental (anterior) y el político y económico; así como de los vínculos existentes entre los países de América Latina y los de Africa y Asia, que utilizan las herramientas occidentales para su liberación. Finalmente, el Seminario pretenderá el fortalecimiento de un latinoamericanismo militante, depurado de la intervención estadounidense, frente al panamericanismo que ésta propone. 
En definitiva, el Seminario intentaba lo que Francisco Miró Quesada ha calificado como un verdadero "redescubrimiento de América", lo que ya veíamos en Gaos, afirmando que la Historia de las Ideas se erigió en los años cuarenta como algo puramente característico del pensamiento latinoamericano, que en los años sesenta va a consolidarse definitivamente con el surgimiento de un pensamiento de liberación. ${ }^{36}$

Para comprender lo que sigue es preciso volver a contextualizar en este momento. Efectivamente, desde los años cuarenta América había visto nacer toda una serie de reformas políticas, económicas, sociales y culturales que intentaban responder a la propia originalidad autóctona. Políticamente, asistimos a la denominada era de los populismos. En la economía se impulsan procesos de modernización, asistimos al desarrollo de las primeras políticas de industrialización sustitutiva de importaciones, y se constituye la Comisión Económica para América Latina (CEPAL). Comienzan a surgir organismos integracionistas, agrupaciones indígenas; se crea el Congreso Episcopal Latinoamericano (CELAM), etc. Lo que hemos denominado surgimiento de una toma de conciencia sobre la propia realidad, parece irse plasmando en formas e instituciones más o menos peculiares en todos los ámbitos y por todos los países de la región. Sin embargo, enseguida comienzan a apreciarse las contradicciones que el propio proceso iba generando. Nuestra hipótesis, si se nos permite tal grado de abstracción, con los problemas que ésta conlleva, es que dicha toma de conciencia, que contaba con una sólida base anterior, se ha visto acelerada, muchas veces desde fuera, y excesivamente formalizada. Era como si en lo que fuera germen informe y lleno de posibilidades, se hubiese tratado de dar forma, de madurarse anticipadamente, elevándolo a rango de proceso consolidado. Las formas irán separándose cada vez más de la realidad y en los años sesenta asistimos a una radicalización que, intentando acercarse de nuevo a la realidad, sólo consigue separarse aún más de ella, y es afrontada con medios indirectos, cuando no con

36 Miró Quesada, Francisco: Proyecto y Realización del Filósofo Latinoamericano, 1981, cap. IV. 
violencia, y sin soluciones de fondo. El fracaso de los planes de desarrollo, de la industrialización y de la modernización económica, se palpa ya a mediados de los cincuenta. En 1959 triunfa la Revolución Cubana, queriendo ofrecer una salida distinta para los problemas de la región, y es enfrentada mediante soluciones como la Alianza para el Progreso (ALPRO), muerta antes de nacer, lo que de nuevo denuncia el fracaso de soluciones foráneas para la propia realidad. Surgen nuevos conatos revolucionarios, se producen golpes de estado y, ya en los años setenta, el panorama político regional vuelve a verse salpicado por las dictaduras. En el ámbito teórico-económico, por su parte, de la CEPAL nace la Teoría de la Dependencia; en el religioso, surge la Teología de la Liberación.

Así expresados, los hechos parecen reflejar un mecanicismo cuasi determinista que en realidad no tienen. No obstante, nuestra intención carece de pretenciosidad, y con lo anterior sólo hemos querido trazar las líneas básicas de lo que podría ser una hipótesis de investigación sobre una realidad cuyo estudio aún no se ha enfrentado, pero cuyas manifestaciones evidentes permiten la posibilidad de intuir la presencia de importantes interrelaciones en el sentido indicado. La conclusión más importante, pues, es la necesidad de llevar a cabo la susodicha investigación, sacando a la luz nuevos elementos que permitan enjuiciar con mayor claridad y precisión una realidad dinámica y compleja.

Lo que hemos conseguido con este ejercicio ha sido abrir la posibilidad de insertar el surgimiento en los años setenta de un Pensamiento de Liberación dentro del Movimiento de Historia de las Ideas en un contexto más general. Esto es, siguiendo el desarrollo teórico propuesto por José Gaos, ubicar el pensamiento dentro de la historia de las ideas y comprender ésta como parte de la historia general. La América que en los años treinta y cuarenta parecía haber tomado conciencia de sí misma y comenzaba a aplicar soluciones para los problemas de su propia realidad, no había sido capaz de afrontar eficazmente su nueva circunstancia. Si nuestra hipótesis es cierta, las nuevas formas se alejan cada vez más de la realidad, incluso llegan a vivir de espaldas a ella. Del Movimiento de Historia de las Ideas surge una corriente que denuncia esta nueva situación. 
Es la encabezada por el peruano Augusto Salazar Bondy, que en 1968 publica su obra ¿Existe una Filosofía Americana? La pregunta no es nueva en absoluto, pero sí lo será la forma en que va a ser contestada. Años atrás habíamos visto desarrollarse una verdadera euforia, convertida luego en obsesión por dar respuesta a una cuestión cargada de un contenido que transciende lo meramente filosófico. Se trataba de sondear en la realidad presente y pasada en busca de formas peculiares que ofreciesen la posibilidad de dar una respuesta afirmativa a la pregunta en el presente. Había que crear una filosofía útil para el desarrollo de la vida del americano y para la conformación definitiva de formas nacionales, capaces de situarse en el más alto nivel de parangón del orden internacional.

Decíamos que dentro de este panorama, lo que estaba sucediendo en el ámbito del pensamiento parecía responder a un proceso más general. Veíamos también cómo José Gaos se apartaba del movimiento que él mismo había creado, entendiendo que empezaba a confundir los medios con las finalidades. Los pensadores debían limitarse a ejercer su labor, nunca denodarse en defender aquello que sólo la historia podía decidir. Esto es, la utilidad de su labor. La nueva actitud venía a ser una especie de intento por conseguir que la realidad respondiese a las teorías que se habían ido elaborando para comprenderla, para ello se realizan verdaderas piruetas teóricas, abstrayendo la labor intelectual, en vez de ponerla al servicio de la realidad. Augusto Salazar Bondy y la Filosofía de la Liberación propusieron la ruptura de esta situación, pero, a la postre, no significaron más que un continuismo radicalizado que coadyuvó al languidecimiento del movimiento. Enlazando con el pensamiento clásico de la liberación, con Freud y Marx, van a denunciar una estructura social que, además de dependiente, produce su propia alienación. Se puede decir, utilizando la terminología al uso, que se había creado una nueva dependencia, aún más grave y profunda y, además, no reconocida. América había formado una nueva imagen de sí misma que no respondía tampoco a la realidad, producto de haber sobreestimado éstạ, abriendo así una nueva y aún más abismal brecha entre los objetivos y las posibilidades. En síntesis, se trataba de una crítica a la sociedad capitalista, incluida dentro de un 
movimiento que tradicionalmente se ha conocido como "El Despertar del Tercer Mundo". Esta idea completa la contextualización histórica del pensamiento que iniciábamos anteriormente.

No vamos a adentrarnos más en un desarrollo al que sólo hemos querido acercarnos como aproximación, tanto porque ello nos supondría alejarnos de nuestro objeto de estudio, como por el hecho de que se trata de temas que precisan una revisión con mayor profundidad. Lo que aquí nos interesa es analizar la forma en que todo esto va a afectar a lo que hemos denominado la modernidad del legado de Ortega en América. Dice Augusto Salazar Bondy:

"La filosofía como tal es un producto que expresa la vida de la comunidad, pero puede fallar en esta función y, en lugar de manifestar lo propio de un ser, puede desvirtuarlo. Se da según esto el caso de una filosofía inauténtica". ${ }^{37}$

Salazar Bondy arremete por tanto contra la ilusión de autenticidad que había vivido América, descubriendo en ella un encubrimiento aún mayor de su propia realidad, y lo cierto es que tenía parte de razón. Era como si la obsesión por lo auténtico y lo original hubiese calado de tal forma en el debate y en la labor intelectual, que éste se alejaba cada vez más de la realidad, convirtiéndose en la más inauténtica de sus manifestaciones. Pero ni Bondy ni la Filosofía de la Dependencia, como también se denomina, son ajenos al proceso que cuestionan. De un lado, cometen el error de aplicar modelos foráneos como soluciones internas, reduciéndolo todo a un problema de dependencia económica. De otro y paralelamente, no fueron capaces de comprender que donde primero había que actuar era en el interior, dedicándose en exceso a cuestionar actitudes exteriores contra las que poco podía hacer su escasa fuerza, cuando además éstas sólo eran parcialmente culpables de los resultados finales que se denunciaban. Finalmente, se enzarzaron en una lucha sin sentido con sus oponentes, distanciando aún más a ambas partes de la realidad. De igual forma que unos negaban la existen-

37 Salazar Bondy, Augusto: ¿Existe una Filosofía Americana?, México, 1968, página 112 
cia de una filosofía propia, otros la afirmaban. Ambos discutían sobre algo que no estaba dentro de sus posibilidades decidir.

La historiografía ha dicho que el circunstancialismo historicista de Gaos recibe ahora su primera crítica importante; pero, como hemos podido apreciar, lo cierto es que de hacer algo, el proceso lo reafirma. En múltiples ocasiones hemos repetido el cuestionamiento que Gaos hace del curso que estaba tomando el movimiento del que él era promotor y el tiempo, la historia -como él gustaba decirparece querer darle la razón. El intelectual no tenía capacidad para decidir sobre algo que sólo la historia podía dirimir. Esto supone volver al Ortega de la Meditaciones del Quijote cuando afirmaba que la historia intelectual de los españoles, aquí diremos latinoamericanos, es la historia de un fracaso, y que sólo reconocida como tal podremos entender su verdadero significado. Lo que en su momento pareció el inicio de un fructífero movimiento intelectual, languidecía víctima de la nueva circunstancia (de ahí la necesidad expuesta por Gaos de hacer historia de las circunstancias), la misma que propició su surgimiento. Leopoldo Zea se denoda en afirmar la existencia de una filosofía americana, frente a Augusto Salazar Bondy, ${ }^{38}$ y el Movimiento de Historia de las Ideas, a la vez que va defendiéndose de la crítica, no tiene problemas para asumirla por sus rasgos más externos; es decir, utilizando aquellos elementos metodológicos que parecían válidos para completar las labores de estudio. Pero el debate se había intelectualizado y el movimiento jamás recobrará su vitalidad. La realidad demandaba un pensamiento útil, pero el pensamiento, en vez de afrontar su misión, parecía dedicarse a defender una utilidad intrínseca y de espaldas a la misma.

\section{Conclusión. La modernidad del legado filosófico de Ortega}

Decíamos en la introducción que la intención de este trabajo permitía reconocer dos partes conscientemente diferenciadas. Una

38 Para el debate Zea-Bondy ver la obra de Bondy citada anteriormente y, Zea, Leopoldo: "Dependencia y liberación de la filosofía americana", en Filosofía y Cultura latinoamericanas, Caracas, 1976. 
primera intentaba analizar la forma en que el pensamiento de Ortega llega a América, desarrollándose allí mediante la reinterpretación que José Gaos hace del mismo, tras exiliarse en México. En esta realidad que tomaba conciencia de sí misma, el legado filosófico de Ortega ofrecía así la posibilidad de una filosofía útil a la vida y a un desarrollo nacional que buscaba sus raíces en la tradición intelectual y en la historia propia, aún sin despreciar las aportaciones exteriores. A través del legado filosófico de Ortega, el intelectual encontraba su papel, no sólo en la reflexión latinoamericana sobre sí misma, sino también en la elaboración de un pensamiento útil para la realidad social.

En una segunda parte intentábamos una aproximación a las líneas esenciales que caracterizaban el desarrollo histórico del movimiento generado por el legado filosófico de Ortega, a través del impulso que la labor de José Gaos en México iba a dar a los estudios sobre el pensamiento americano, intentando descubrir las razones por las que dicho movimiento no sólo no resultó tan fructífero como se esperaba, sino que además debe ser juzgado como un fracaso en el más puro sentido orteguiano.

Ante esta situación quedan varias posibilidades de análisis que aquí hemos convertido en interrogantes. Quizás las condiciones no eran las más idóneas y el pensamiento se vio falto de la condición suficiente para su eficacia; acaso la nueva visión de la realidad estaba demasiado viciada por lo que estaba sucediendo fuera de ella y la toma de conciencia que se hace sobre la misma responde más a imperativos externos que a una verdadera necesidad interna. Es posible, finalmente, que la extrapolación que del pensamiento de Ortega se hace a América fuese en realidad una nueva importación inadecuada para la propia realidad. Probablemente en la combinación de todos estos factores pueden encontrarse algunas respuestas.

Desde estas conclusiones, lo que ahora pretendemos es apuntar la modernidad que, entendemos, tiene aún el legado de Ortega para la situación que en la actualidad atraviesa América Latina. Para ello volvemos a retomar los orígenes de su pensamiento y la reinterpretación que de él hacía José Gaos. 
En realidad, estudiar el papel de un movimiento intelectual latinoamericano; puesto que en ningún momento hemos pretendido identificar con él la totalidad del pensamiento de algo más de medio siglo en América Latina, y analizar la modernidad del legado de Ortega, ha quedado suficientemente demostrado que son dos cosas distintas. Según pudimos apreciar, aquél se separa paulatinamente de éste e, incluso, llega a defraudarlo. En este capítulo de conclusiones nos dedicaremos exclusivamente, pues, al segundo de los ejercicios posibles, lo qué es en realidad nuestro tema de estudio.

Escribía Juan Marichal hace algún tiempo en el diario El País un artículo titulado "La Triple Alianza", en el que se defendía la necesidad que América Latina tiene de una verdadera reconstrucción en todos los órdenes, así como el papel que España podía y debía jugar inexorablemente en ella, y no por mero altruismo, sino por su propio beneficio. Aquélla sería - según Marichal- la única forma por la que España podría alcanzar el papel que desde hace algún tiempo viene reivindicando en la esfera internacional. ${ }^{39}$

Es cierto que cualquier solución eficiente para los problemas de América Latina pasa necesariamente por el apoyo exterior, y que España debería potenciar la posibilidad de ejercer el papel de puente y enlace para un compromiso internacional que los afrontase, fuera de la retórica y de la parafernalia que se prodiga en los actos de preparación del Quinto Centenario. Pero de nada habrá de servir una acción como tal, de por sí difícil de llevar a cabo, si América no colabora por medio de un sincero compromiso con su propia realidad.

De un modesto estudio como éste se deduce que no basta con tomar conciencia de los problemas. Es preciso aplicar los resultados de la misma para que las soluciones propuestas tengan eficacia. Decía Octavio Paz:

“(...) La historia nos ayuda a comprender ciertos rasgos de nuestro carácter a condición de que seamos capaces de aislarlos y denunciarlos previamente. Nosotros somos los únicos que podemos contestar a las preguntas que nos hacen la realidad y nuestro propio ser". ${ }^{40}$

39 Marichal, Juan: "La Triple Alianza", El Pais, Madrid, sábado, 22 de abril de 1990.

40 Paz, Octavio: El laberinto de la Soledad, México, 1988, pág. 67. 
Efectivamente, el mismo Paz, García Márquez y otros intelectuales latinoamericanos no han cesado de repetir desde hace algún tiempo que la realidad americana no se entiende con ojos europeos, de ahí que toda solución que llegue desde fuera, o desde dentro, pero sin partir de la propia realidad, esté destinada al fracaso. América, sin embargo, tampoco ha ayudado a que se la comprenda. Una región que en la actualidad adolece de un fuerte desequilibrio económico-social y en la que inequidad y pobreza son dos de los grandes problemas sin resolver, está reaccionando tratando de adaptar formas político-sociales y económicas importadas de realidades exteriores, donde cumplen el objetivo de imponer estabilidad socioeconómica y política al sistema. De nuevo, por tanto, los sistemas que por doquier se han ido estableciendo en los distintos países de la región, parecen hacerlo de espaldas a los problemas y a la realidad del desarrollo histórico-social interno. "La mentira política se instauró en el seno de nuestro pueblos casi constitucionalmente". ${ }^{41}$

Decía Octavio Paz, como en su momento había dicho Samuel Ramos:

"En último término, la imitación ha determinado (...) un efecto (...) fundamental para entender nuestro carácter. Consiste en el desdoblamiento de nuestras vidas en dos planos separados, uno real y otro ficticio (...) Por ejemplo, cuando es promulgada una constitución, la realidad política tiene que ser apreciada a través de aquélla (la realidad política y social); pero, como no coincide con sus preceptos, aparece siempre como inconstitucional (...) Si la vida se desenvuelve en dos sentidos distintos, por un lado la ley y por otro la realidad, ésta última será siempre ilegal". ${ }^{42}$

Tanto en Paz como en Ramos encontraron uno de los diagnósticos más lúcidos de lo que quizás es el gran problema histórico de América Latina. Solucionarlo sólo es posible mediante una verdadera toma de conciencia que definitivamente dé paso a una actitud renovada frente a la realidad. Aquí es donde el legado de Ortega muestra toda su modernidad, y tanto en el sentido de la necesaria

41 Ibídem, pág. 111.

42 Ramos, S.: El perfil..., pág. 24. 
asunción de la propia realidad y de la circunstancia inmediata, única forma posible de superarla, como en el compromiso que España debiera mantener para la solución de los problemas de América Latina.

La actual imbricación de los procesos políticos y económicos mundiales y las implicaciones que el exterior tiene en los asuntos de la región, hacen inviable cualquier solución que no cuente con el necesario apoyo internacional. Dicho apoyo, sin embargo, no puede esperarse de una forma pasiva, ni conseguirse olvidando la propia situación interna. Ello sólo significaría seguir viviendo de espaldas a la realidad, con el consiguiente agravamiento de los problemas.

A nadie escapa la dificultad de ofrecer soluciones, más aún, de hacerlas realmente eficientes, pero sin que América no afronte de una vez su verdadera realidad y sus posibilidades, adecuando a ellas los objetivos, nada podrá conseguirse. Aquí es donde el legado de Ortega manifiesta su modernidad, y lo hace en dos sentidos distintos pero complementarios. De un lado, en la referida necesidad de una toma de conciencia de los propios problemas, así como en el papel que el intelectual debería jugar en ella, reconociendo la validez de su propia tradición y ejerciendo una labor verdaderamente útil para la sociedad. De otro, en la posición que España podría y debería asumir en los problemas de América Latina. Para ello es necesario recordar que toda una época de efervescencia intelectual, quizás la más fructífera de nuestra historia, justificada y articulada en torno al pensamiento de Ortega, y precisamente la de mayor vocación europeísta, comprendió con el exilio la verdadera unidad existente entre las realidades hispanas de ambos lados del Atlántico. La España plenamente europea podría así, no sólo ejercer la labor que reivindicaba Juan Marichal, sino también colaborar en la necesaria toma de conciencia, indispensable para cualquier solución eficaz. 